\title{
Exploring the Influence of Geographic Region and Cultural Indulgence on Tactile Behaviors
}

\author{
Michael J. Miller ${ }^{1}$, Peter A. Andersen ${ }^{2}$, Dana L. Rogers ${ }^{3} \&$ Kate S. Kurtin ${ }^{4}$ \\ ${ }^{1}$ Department of Psychology, Providence College, 1 Cunningham Square, Providence, RI 02918, USA \\ ${ }^{2}$ San Diego State University, 5500 Campanile Drive, San Diego, CA 92182, USA \\ ${ }^{3}$ Communication Department, Southern Connecticut State University, 501 Crescent Street, New Haven, CT \\ 06515, USA \\ ${ }^{4}$ Communication Studies, California State University Los Angeles, 5151 State University Drive, Los Angeles, \\ CA 90032, USA
}

Correspondence: Michael J. Miller, Department of Psychology, Providence College, 1 Cunningham Square, Providence, RI 02918, USA.

Received: December 13, 2021

Accepted: January 17, 2022

Online Published: January 24, 2022

doi:10.5539/ijps.v14n1p37

URL: https://doi.org/10.5539/ijps.v14n1p37

\begin{abstract}
In this study, touch behavior was monitored via live-feed webcams in 18 bars, spread across 5 continents (North America, South America, Europe, Australia, and Asia) for 213 hours. Our findings offer support for a link between equatorial proximity (measured by latitude) and cultural indulgence with more tactile communication. In cultures where indulgence versus restraint was more normative, those perceived as females initiated more touch in both opposite- and same- sex dyads. Moreover, in cultures closer to the equator, there was an increase in touch frequency and the number of body locations touched. Housed within these findings is the idea that geographical location may play a predictable role in motivating the development of cultural communication norms and behaviors. We consider the influence of sunlight, topography, history, and other culture-specific forces on the development of touch norms.
\end{abstract}

Keywords: tactile, latitude, culture, indulgence, touch

\section{Introduction}

At all stages of human development, physical touch provides a direct gateway to interact with our environments and with others. Compared to verbal and other nonverbal forms of communication, touch plays a uniquely potent role in social bonding (Andersen, 2011; Miller, Denes, Diaz, \& Buck, 2014), conception (Montagu, 1972), child-rearing (Sorokowska et al., 2021), and aggression (Field, 1999). Consequently, physical contact is distinctively shaped and regulated by one's physiology and environment (Montagu, 1972). For example, consider the variation in clothing worn outdoors across regions, thinner versus thicker layers of clothing provide a more direct route for skin-to-skin contact, potentially leading to more consequential touch in public settings. Exploring variations such as these have been instrumental in helping to understand how touch communication norms develop across cultures and topographies.

Scholars have approached cultural variation in touch and proxemic behavior using a variety of methods (i.e., experiments, surveys, body charts, interviews, observations, photographs, and recordings) and antecedent variables, including: climate (latitude) (Andersen, 2011; Andersen, Lustig, \& Andersen, 1990), temperature (IJzermann \& Semin, 2009; McDaniel \& Andersen, 1998; Sorokowska et al., 2021), cultural collectivism versus individualism (Lustig \& Andersen, 1990; Shutter, 1977), liberalism (Sorokowska et al., 2021), religiosity (Sorokowska et al., 2021), gender (Andersen, Andersen, \& Lustig, 1987; McDaniel \& Andersen, 1998; Remland, Jones \& Brinkman, 1995; Sorokowska et al., 2017), age (Sorokowska et al., 2017), and spoken language (Remland et al., 1995). In general, findings suggest that touch communication increases in higher temperatures, warmer climates, and locations closer to the equator, and within more individualistic, feminine, less conservative, and less religious cultures. Touch behavior also increases among those who identify as younger, female, and liberal. Although we have learned a great deal about touch communication around the globe, there are still significant gaps and inconsistencies in our understanding of how culture motivates variations in touch behavior. 
Recent, self-report research on interpersonal touch has allowed researchers to better understand how individual and cultural variables influence how often and in what ways people use physical touch across their relationships and interactions (Sorokowska et al., 2017; Sorokowska et al., 2021; Suvilehto, Glerean, Dunbar, Hari, \& Nummenmaa, 2015; Suvilehto et al., 2019; Watkins et al., 2019). These studies provide some insight into cultural touch perceptions and are instrumental in understanding private touch communication, which cannot be observed naturalistically. However, the self-report method provides more in the way of individual perceptions and motivations and less in the way of actual behavior, especially in public spaces where social norms uniquely regulate touch behavior.

Collectively, the early assertions and subsequent research regarding what drives the development of tactile communication norms within and across cultures provide a robust, yet still unrefined, set of potential antecedents of touch communication. Specifically, there is a need for more methodologically and theoretically current, naturalistic data on touch behavior across cultures. To these ends, the current study utilizes live-stream digital observations across a range of latitudes and cultural indulgence indexes (a recently identified indicator of cultural norms related to interpersonal restraint versus indulging) to examine variations in tactile behavior. Latitude and indulgence were chosen for three primary reasons: 1) each variable has been previously shown to be related to cultural norms and behaviors including nonverbal and tactile behaviors; 2) latitude and indulgence orientations are easily determined if data are collected in a single cultural location; 3) if latitude and/or cultural indulgence are systematically associated with touch, they may help shed light on the origins of cultural norms and the differences in communication across cultures.

\section{Literature Review}

\subsection{Latitude and Touch Communication}

Much of the work related to latitude, climate, and touch behavior over the last 50 years was spurred on by Hall's (1966) research that marked areas around the globe as high or low context cultures. Hall's characterization of context referred to the explicit and implicit amounts of information put into communicative interactions. It is argued that high context cultures like the Japanese require less in-depth (explicit) communication in daily interactions because of their strong and intensive information networks related to collective ties and relationships. This contrasts with low-context cultures like the United States, where Hall (1966) contends that personal relationships and networks are more compartmentalized resulting in a need for more explicit communication in daily interactions. Touch communication (especially public touch), Hall (1966) further argues, is greater in low context cultures where immediacy behaviors are needed to provide context clues during interactions.

Interpretations of Hall's $(1966$; 1973) claims over the past decades seem to fall between over- and under-generalizations. Remland et al. (1995) and McDaniel and Andersen (1998) have pointed out that many scholars (including Hall) have taken Hall's (1966) initial interpretations too literally. As McDaniel and Andersen (1998) indicate, Hall's (1966) original ideas most heavily focused on touch behaviors within social or consultative contexts and "have subsequently [been] applied... to all forms of intercultural touch, without qualification or context" (p. 69). Thus, although useful as basic guides, Hall's (1966) original conceptualizations of high and low context cultures have not received ample support regarding tactile communication.

More recent research highlights climate, and by association, latitude as a significant predictor of differences in touch behaviors across the U.S. (Andersen et al., 1990) and around the globe (Andersen \& Wang, 2006; Field, 1999; Miller, Commons \& Gutheil, 2006; Shutter, 1977; Sorokowska et al., 2017; Sorokowska et al., 2021). Findings from these studies offer support for a link between equatorial closeness (measured by latitude) and higher temperatures with more tactile communication and general comfort with touch. Andersen (2011) provides several explanations for why tactile contact increases closer to the equator, indicating that skin sensitivity, the influence of sunlight on one's body, outdoor activity, sociability, decreased clothing, and selective immigration may all play a role in influencing tactile differences among cultures (p. 9).

Methods used to garner data on tactile behavior and latitude include naturalistic observations, frame-by-frame photographs, interviews, and surveys. For example, McDaniel and Andersen (1998) observed individuals in an international airport during departures, while Shutter (1977) photographed individuals frame-by-frame in a public location. These methods have been criticized as being less accurate than the use of video recordings in naturalistic settings (Remland et al., 1995). Studies that did use video recordings (Remland et al., 1995) failed to find significant differences between individuals in the Netherlands, England, and France, despite latitudinal differences. These recordings, however, have been criticized for targeting interactions within a context that entailed very little touch and had minimal disparities in latitude (i.e., individuals observed in France were not from Southern France) (Andersen, 2011) and the three countries are all in middle latitude European countries of 
the Northern Hemisphere. Thus, there has been some difficulty in reconciling the trade-offs between contexts, methods of recording, and diversifying locations.

A more recent survey study of 14,478 participants from 45 countries found that a higher prevalence of touch (as reported by respondents) occurred in warmer versus colder regions (Sorokowska et al., 2021). The study asked participants to reflect on their touch communication in the past week and examined features of participants, their relationships, and the cultural they lived in. The study was limited in that the prevalence of touch was measured as an either or and did not provide robust frequency indicators. For example, respondents could only answer yes or no to whether they hugged a romantic partner in the last week (Sorokowska et al., 2021). That said, the findings represent the largest and most globally representative examination of personal, relational, and cultural perceptions related to touch behavior; further findings related to cultural indulgence are discussed in the following section.

With the current mix of findings, a fairly strong argument can be made for the influence of latitude and temperature on touch behaviors with the caveat that naturalistic observational techniques, locations, and contexts involving touch need refinement to be more accurate and reflective of multiple external influences. If it is shown that touch differs systematically across latitude, then a key antecedent of culture will have been identified. To replicate and extend past research highlighting the potential influence of climate and latitude on touch, the present study conducted naturalistic observations via bar webcams (high resolution, $60 \mathrm{fps}$ ) on a live feed; we predicted the following:

H1a. Global latitude will be negatively related to touch frequency during interpersonal interactions.

H1b. Global latitude will be negatively related to the number of body locations touched during interpersonal interactions.

\subsection{Cultural Indulgence Orientation and Touch Communication}

The cultural dimensions of Hofstede (2001) are well established for country-level comparisons of power distance, uncertainty avoidance, individualism/collectivism, and masculinity/femininity. In 2010 a fifth and sixth component, identified from Minkov's analysis of the World Values Survey data, were added to Hofstede's initial four (Minkov \& Hofstede, 2011). The sixth dimension has potential to influence haptic research and has been labeled indulgence versus restraint (Minkov \& Hofstede, 2011). Indulgent societies more readily seek out pleasure without muting natural sensation-seeking-needs that lead to positive emotions; whereas, restrained societies try to refrain from pleasure-seeking through more stringent and restrictive social norms- regulating positive emotions (Minkov \& Hofstede, 2011). Further, Gokmen, Baskici, and Ercil (2020) provide data to suggest that more indulgent societies may have difficulties restraining personal pleasure-seeking behavior through social norms. More indulgent cultures, therefore, might be expected to have less restrictions on public touch behaviors that are a source of satisfaction for individuals.

Some of the primary functions of touch (i.e., procreation, exploration (play), and nurturance) revolve around personal satisfaction and the gratification of natural needs. Research examining the daily life of the Fore, a primarily agricultural tribe in Papua New Guinea, illustrates a culture of tactile indulgence (Sorenson, 1979). For example, Fore women were observed in nearly constant contact with their infants, making their breasts available for infants to "indulge" at their leisure. The early tactile behavior of the Fore was shown to persist, in both play and courting, into adulthood.

In more modern societies, regulation of touch behavior appears linked to cultural conservatism and religiosity (Sorokowska et al., 2021). Specifically, Sorokowska et al. (2021) found that individuals in cultures with stronger religious norms and greater conservatism reported less frequency and diversity in affective touch (embrace, stroke, kiss, or hug) with partners, friends, and youngest children during a one-week period. The authors argue that conservatism, with its relationship to disgust sensitivity, relationship restraint/ withdrawal, and lower emotional expressiveness may negatively impact affective touch communication. In turn, religiosity may further inhibit affective touch by restricting sexuality, condemning promiscuity, premarital sex, and sexual intercourse out of the fertile phase (Sorokowska et al., 2021). These beliefs generally align with characterizations of cultures that are high in restrain versus indulgence. In addition, they are associated with general decreases in touch frequency along with the number of body locations that people are willing to touch. It stands to reason that they may also contribute to touch norms related to same sex and cross sex touch frequency and variation.

To date, there is little research specifically examining the relationship between a culture's propensity for touch and their general cultural indulgence, though a relationship between indulgence and touch would be consistent with past studies on indulgence and restrictive social norms, and draws parallels to findings related to 
conservatism, religiosity, and the permissibility of touch communication in varying cultures. To examine the potential role of indulgence, we pose the following research questions.

RQ2a. Is touch frequency dependent on a cultural indulgence orientation?

RQ2b. Are the number of body locations touched dependent on a cultural indulgence orientation?

RQ2c. Is cross-sex touch initiation dependent on a cultural indulgence orientation?

RQ2d. Is same-sex touch initiation dependent on a cultural indulgence orientation?

\section{Method}

\subsection{Participants}

No studies in this manuscript were preregistered. Touch interactions were recorded in 18 bars, spread across 5 continents (North America, South America, Europe, Australia, and Asia) for 213 hours. All locations clearly posted to patrons that live-feed cameras were in operation in specific areas in their establishments (cameras were owned and operated by establishments). In addition, we did not collect or record any personal data from those observed. This sample was chosen based on the availability of quality digital video cameras (minimum of 60 frames per second frame rates), clearly labelled in establishments, across a diverse range of latitudes and longitudes with similar bar set-ups (i.e., arrangement and number of tables and chairs).

The sample provided 350 cases (across 18 locations) which exceeded our power estimates of 162 cases minimum to observe a moderate effect size of $.15(F=4.051)$ with an alpha of .0083 (see results for alpha calculation). Each establishment had to serve alcohol and be open Thursday through Saturday between the hours of 9 pm-12 am, through the months of March, April, May, and June in 2015. Coders recorded 1502 touch interactions that were directed at 11 different body locations (arm, butt, thigh, head, face, leg, shoulder, chest, back, lips, and hand). Touch interactions were initiated by those perceived by coders as males and females in the following manner: 455 male-to-female, 495 female-to-male, 262 female-to-female, and 290 male-to-male. The data set, along with the codebook are available on the following data repositories: SPSS data set (https://figshare.com/s/9045304554381eb62306), (https://figshare.com/s/a54cab556ecd2455215a).

\subsection{Tactile Coding Procedures}

Fourteen trained undergraduate student-researchers coded cams on Thursdays, Fridays, and Saturdays between the hours of $9 \mathrm{pm}$ and $12 \mathrm{am}$ (bar cam location time). Coders recorded touch type on a second-by-second basis using a modified list (Figure 1) of touches developed from Jones and Yarborough's (1985) interpersonal interaction study. Coders also recorded the body parts that came into contact during a touch. Touch was operationalized as any deliberate physical contact between individuals, including skin-to-skin, skin-to-clothing, and clothing-to-clothing, contact. Touch initiation was determined by which member of a dyad was first to begin a movement that resulted in physical contact. In cases of mutual touch, observers judged initiation based on the first movement they perceived. Also using observation, perception, and available cues, coders recorded the "perceived sex" of those communicating (p-sex, p-female, p-male henceforth). Contextual information, such as the time, date, lighting, country, group size, standing/sitting, departing/arriving/socializing, and bar name were also recorded. Tables 1 and 2 show the dyadic touch opportunities (standardized per half hour) in each country along with the number of touches observed. Touch opportunities were standardized to balance comparisons across geographic locations; specifically, we were interested in how much touch communication occurred given the same amount (or opportunity) for touch to be enacted. 
Table 1. Touch Interactions by Opportunities in Cross-Sex Dyads

\begin{tabular}{lllll}
\hline & Indulgence & Absolute & \multicolumn{2}{l}{ Touches $\backslash$ Opportunities } \\
\cline { 2 - 5 } Location & Index & Latitude & M-F & F-M \\
\hline Australia-Cairns & 71 & 16.92 & $15 \backslash 12$ & $10 \backslash 12$ \\
Belgium-Hoeselt & 57 & 50.85 & $13 \backslash 12$ & $6 \backslash 12$ \\
Costa Rica & N/A & 9.64 & $29 \backslash 18$ & $45 \backslash 18$ \\
Germany-Berlin & 40 & 52.50 & $31 \backslash 25$ & $12 \backslash 26$ \\
Italy-Venezia & 30 & 45.44 & $17 \backslash 15$ & $16 \backslash 15$ \\
Mexico & 97 & 20.62 & $12 \backslash 9$ & $23 \backslash 9$ \\
Norway & 55 & 59.91 & $10 \backslash 8$ & $6 \backslash 8$ \\
Romania & 20 & 44.44 & $0 \backslash 0$ & $0 \backslash 0$ \\
Spain-Barcelona & 44 & 41.38 & $40 \backslash 26$ & $30 \backslash 26$ \\
Spain-Gracia & 44 & 41.40 & $11 \backslash 8$ & $10 \backslash 8$ \\
Spain-Malaga & 44 & 36.60 & $25 \backslash 25$ & $39 \backslash 25$ \\
Switzerland & 66 & 47.71 & $24 \backslash 18$ & $22 \backslash 18$ \\
Thailand-Bophut & 45 & 9.52 & $32 \backslash 25$ & $38 \backslash 25$ \\
Thailand-Phuket & 45 & 7.98 & $5 \backslash 4$ & $14 \backslash 4$ \\
UK-Gwynedd & 69 & 53.23 & $35 \backslash 35$ & $45 \backslash 35$ \\
US-Florida & 68 & 30.16 & $89 \backslash 30$ & $90 \backslash 30$ \\
US-Virgin Islands & 68 & 18.33 & $47 \backslash 16$ & $59 \backslash 16$ \\
US-Washington & 68 & 47.61 & $20 \backslash 17$ & $30 \backslash 17$
\end{tabular}

Note: Touch opportunities were standardized as every half hour. $\mathrm{M}-\mathrm{F}=$ male to female, $\mathrm{F}-\mathrm{M}=$ female to male.

Table 2. Touch Interactions by Opportunities in Same Sex Dyads

\begin{tabular}{lllll}
\hline & Indulgence & Absolute & \multicolumn{2}{l}{ Touches $\backslash$ Opportunities } \\
\cline { 2 - 5 } Location & Index & Latitude & F-F & M-M \\
\hline Australia-Cairns & 71 & 16.92 & $30 \backslash 10$ & $26 \backslash 10$ \\
Belgium-Hoeselt & 57 & 50.85 & $7 \backslash 7$ & $18 \backslash 19$ \\
Costa Rica & N/A & 9.64 & $16 \backslash 12$ & $22 \backslash 13$ \\
Germany-Berlin & 40 & 52.50 & $5 \backslash 14$ & $1 \backslash 10$ \\
Italy-Venezia & 30 & 45.44 & $10 \backslash 13$ & $16 \backslash 10$ \\
Mexico & 97 & 20.62 & $6 \backslash 3$ & $19 \backslash 9$ \\
Norway & 55 & 59.91 & $8 \backslash 8$ & $2 \backslash 5$ \\
Romania & 20 & 44.44 & $0 \backslash 0$ & $13 \backslash 4$ \\
Spain-Barcelona & 44 & 41.38 & $16 \backslash 12$ & $11 \backslash 13$ \\
Spain-Gracia & 44 & 41.40 & $0 \backslash 3$ & $8 \backslash 8$ \\
Spain-Malaga & 44 & 36.60 & $17 \backslash 20$ & $11 \backslash 13$ \\
Switzerland & 66 & 47.71 & $6 \backslash 4$ & $33 \backslash 27$ \\
Thailand-Bophut & 45 & 9.52 & $29 \backslash 18$ & $14 \backslash 11$ \\
Thailand-Phuket & 45 & 7.98 & $12 \backslash 4$ & $8 \backslash 4$ \\
UK-Gwynedd & 69 & 53.23 & $24 \backslash 17$ & $45 \backslash 34$ \\
US-Florida & 68 & 30.16 & $32 \backslash 20$ & $21 \backslash 15$ \\
US-Virgin Islands & 68 & 18.33 & $24 \backslash 7$ & $17 \backslash 9$ \\
US-Washington & 68 & 47.61 & $4 \backslash 4$ & $6 \backslash 7$ \\
\hline
\end{tabular}

Note: Touch opportunities were standardized as every half hour. F-F = female to female, $\mathrm{M}-\mathrm{M}=$ male to male. 
The fourteen coders paired up for their first 2 hours of coding so that we could assess their reliability using the SPSS macro KALPHA (Hayes \& Krippendorff, 2007). Specifically, coders were required to code the same bar cam at the same time, but not be in the same room as one another. Reliability was calculated for observed touch instances and locations per half hour. The average of the seven pair's Krippendorff alphas for touch frequency were .78 . The average alphas for touch location frequency were .82 . All pairs had alphas above .74 and were deemed adequately reliable to continue coding on their own.

Since tactile communication can happen quickly, the coding sheet was an electronic spreadsheet (see Figure 1) designed with drop-down lists for each cell (except body location) so that coders could watch and record multiple interactions using minimal keystrokes. The drop-down lists also insured that only prescribed terms were entered into cells. The location of body touches was coded by typing in a few letters of each body location that came into contact, separated by a dash; coders were trained to type enough to code quickly but still differentiate locations reliably (e.g., hand-shou).

\begin{tabular}{|c|c|c|c|c|c|c|}
\hline $\begin{array}{l}\text { Event } \\
\# \\
\text { Every } \\
\text { Touch } \\
\text { or } \\
\text { half } \\
\text { hour }\end{array}$ & $\begin{array}{l}\text { caressing holding, feeling } \\
\text { caressing, prolonged } \\
\text { holding, holding or } \\
\text { pressing against, } \\
\text { prolonged pressing } \\
\text { against, spot touching, pat, } \\
\text { squeeze, joking punch, } \\
\text { accidental touch }\end{array}$ & $\begin{array}{l}\text { body location } \\
\text { (abbreviate) } \\
\text { (e.g., hand-thig } \\
\text { or hand-leg) } \\
\text { TYPE IN }\end{array}$ & $\begin{array}{l}\text { male or female } \\
\text { who touches } \\
\text { whom }\end{array}$ & $\begin{array}{l}\text { Group } \\
\text { makeup } \\
\text { Min 2, } \\
\text { Max } 4\end{array}$ & $\begin{array}{l}\text { Approximate } \\
\text { Clock Time }\end{array}$ & $\begin{array}{l}\text { For Post Analysis } \\
\text { (List number of } \\
\text { touches for each } \\
1 / 2 \text { hour } \\
\text { opportunity to } \\
\text { touch- per dyadic } \\
\text { makeup) }\end{array}$ \\
\hline 1 & spot touching & hand-shou & $\begin{array}{l}\text { female touches } \\
\text { male }\end{array}$ & $\mathrm{m}, \mathrm{f}$ & $10 \mathrm{pm}-10: 30 \mathrm{pm}$ & \\
\hline 2 & pat & hand-back & $\begin{array}{l}\text { male touches } \\
\text { female }\end{array}$ & $\mathrm{m}, \mathrm{f}$ & $10 \mathrm{pm}-10: 30 \mathrm{pm}$ & $\mathrm{mf} 1 ; \mathrm{fm} 1$ \\
\hline 3 & & & & $\mathrm{~m}, \mathrm{f}$ & $10: 30 \mathrm{pm}-11 \mathrm{pm}$ & $\mathrm{mf} 0$ \\
\hline 4 & spot touching & hand-knee & $\begin{array}{l}\text { male touches } \\
\text { female }\end{array}$ & $\mathrm{m}, \mathrm{m}, \mathrm{f}$ & $11 \mathrm{pm}-11: 30 \mathrm{pm}$ & \\
\hline 5 & prolonged pressing against & chest-chest & $\begin{array}{l}\text { male touches } \\
\text { female }\end{array}$ & $\mathrm{m}, \mathrm{f}$ & $11 \mathrm{pm}-11: 30 \mathrm{pm}$ & $\mathrm{mm} 1 ; \mathrm{mf} 2$ \\
\hline 6 & spot touching & hand-leg & $\begin{array}{l}\text { male touches } \\
\text { male }\end{array}$ & $\mathrm{m}, \mathrm{m}, \mathrm{f}$ & $11 \mathrm{pm}-11: 30 \mathrm{pm}$ & \\
\hline 7 & squeeze & hand-elbow & $\begin{array}{l}\text { male touches } \\
\text { female }\end{array}$ & $\mathrm{m}, \mathrm{f}$ & $11: 30 \mathrm{pm}-12 \mathrm{pm}$ & $\mathrm{mf} 1 ; \mathrm{fm} 1$ \\
\hline
\end{tabular}

Figure 1. Touch Interaction Coding Sheet

\subsection{Determining Latitude and Longitude}

To determine the absolute latitude of our locations we entered each location into the website getLatLong.net (n.d.)- negative values were converted to positive values for further analysis. The website provided us with latitude measurements of the angular distance of our locations from the equator in degrees (60 minutes per degree), minutes, and seconds; latitudes ranged from 7.98 to 59.91 with a mean of $38.51(S D=16.10)$.

\subsection{Cultural Indulgence Orientation}

Indulgence scores were garnered from the Indulgence versus Restraint Index (IVR) (Hofstede, 2011); scores ranged from 15 to 97 with a mean of $51.42(\mathrm{SD}=15.17)$. Though culture is further broken down by (Hofstede, 2011) (e.g., individualistic versus collectivist, masculine versus feminine) we focused on indulgence due its theoretical relationship with touch communication.

\section{Results}

Multiple regression analyses were used to examine the overall influence of p-sex, cultural indulgence, and latitude on touch frequency and number of body locations touched. In our models, to account for the potential influence of alcohol we included hour of the day as an independent variable. Similarly, multiple regression models were used to explore our research questions regarding the role of cultural indulgence and latitude in same and cross p-sex tactile initiation. 


\subsection{Multiple Regression Models}

A series of multiple regression models addressed the influence of three independent variables on six dependent variables (model 1 - model 6). A Bonferroni correction of 6 was used on each model alpha to correct for multiple models $(p=.0083)$. The dependent variables, adjusted for the number of touch opportunities, were: total touch (model 1: $R 2=.228, F(3,350)=34.208, p<.001)$; total number of body locations touched (model $2: R 2$ $=.083, F(3,350)=10.486, p<.001)$; total p-male touching $\mathrm{p}$-female $(\operatorname{model} 3: R 2=.058, F(3,350)=7.090, p$ $<.001$ ); total p-female touching p-male (model 4: $R 2=.114, F(3,350)=14.838, p<.001$ ); total p-female touching $\mathrm{p}$-female (model $5: R 2=.107, F(3,350)=13.838, p<.001)$; and total p-male touching $\mathrm{p}$-male (model 6: $R 2=.029, F(3,350)=4.487, p=.004)$. For each of the six models, the independent variables were: latitude, cultural indulgence, and time of day. Descriptive results showed minimal to no multicollinearity between variables in each of the six models- all tests of heterogeneity of variance were not significant and no variance inflation factors were greater than 1.010 (O'Brian, 2007).

\subsection{Time of Day and Touch}

Time of day was significantly and positively related to total touch $(b=.189, p<.001,95 \% C I[.162-.477])$, number of body locations touched $(b=.166, p<.001,95 \% C I[.065, .268])$, p-male-to-p-female touch $(b=.152$, $p=.004,95 \% C I[.042, .216])$, and p-female-to-p-male touch $(b=.138, p<.007,95 \% C I[.039, .239])$. In turn, time of day was not significantly associated with p-female-to-p-female touch $(b=.051, p=.313,95 \% C I$ $[-.029, .089])$ or p-male-to-p-male touch $(b=.013, p=.809,95 \% C I[-.051, .065])$.

\subsection{Latitude and Touch (HIa \& H1b)}

Hypothesis H1a, posited a negative relationship between absolute global latitude and touch frequency during interpersonal interactions in bars. Results from multiple regression model 1 supported H1a, showing that latitude significantly predicted touch frequency $(b=-.359, p<.001,95 \% C I[-.088,-.052])$. Support was also found for H1b (model 2), which predicted that absolute global latitude would be negatively related to the number of locations touched during interpersonal interactions in bars $(b=-.147, p=.005,95 \% C I[-.029,-.005])$. Specifically, when latitude approached zero, touch frequency and the number of locations touched increased significantly.

\subsection{Cultural Indulgence and Touch (RQ2a-RQ2d)}

Research questions $2 \mathrm{a}-2 \mathrm{~d}$ introduced the potential association between cultural indulgence and touch communication within and between groups. Results for research questions $2 \mathrm{a}$ and $2 \mathrm{~b}$ showed that as cultural indulgence increased, touch frequency $(b=.207, p<.001,95 \% C I[.023, .059])$ and the number of body locations touched $(b=.167, p<.001,95 \% C I[.007, .030])$ also increased. Research question $2 \mathrm{c}$ explored differences in the frequency of touch initiation within cross-p-sex dyads. Cultural indulgence did not have a significant association with p-male initiated touch in cross-p-sex dyads $(b=.088, p=.094,95 \% C I[-.001, .018])$ but did have a significant association with p-female initiated touch in cross-p-sex dyads $(b=.163, p<.001,95 \%$ $C I[.007, .030])$. Lastly, cultural indulgence was associated with increased touch initiation in p-female-p-female, same-p-sex dyads $(b=.141, p=.006,95 \% C I[.003, .016])$ but not significantly associated with touch in p-male-p-male, same-p-sex dyads $(b=.109, p=.041,95 \% C I[.0002, .065])$.

\section{Discussion}

Results from the current study address how touch behavior between individuals differs in relation to geographical location and cultural indulgence. In general, latitude and cultural indulgence both showed a relationship with touch frequency/diversity, with some emergent differences between dyads of differing p-sex make-ups. It is also noteworthy, though not surprising that as the hour of the day grew later, touch frequency, the number of body locations touched, and cross p-sex touch, all increased. Since all the locations observed in the study served alcohol, it may be that as individuals drank more, they became more uninhibited toward physical touch (Assaad et al., 2006). It is also plausible that, in cross-p-sex dyads, where there was romantic attraction, the urgency to touch and make a romantic connection increased as the end of the evening approached.

\subsection{Latitude and Touch}

Findings from this study are consistent with past research that has found an association between equatorial distance and touch frequency (Andersen et al., 1990; Andersen \& Wang, 2006; Field, 1999; Miller et al., 2006; Shutter, 1977) and increased temperature and touch frequency (Sorokowska et al., 2021). In general, individuals were observed touching more often and touching each other in more places on each other's bodies in countries closer to the equator. Specifically, touch frequency and the number of body locations touched were highest in places nearest to the equator (Mexico, Thailand, Southern United States, Australia, and Costa Rica) and lowest 
in places furthest from the equator (Romania, Spain, Norway, Switzerland, United Kingdom, Northern Italy, Belgium, Germany, and Northern United States). These results may shed light on the very origins of cultures. Cultures did not develop by accident but were shaped by factors including climate and terrain.

Our findings continue to support the importance of geographical location in explaining tactile behavior across cultures. At present, there is a need for more empirical research directed specifically at measuring and accounting for the variables linking geographical location, culture, and touch behavior. Andersen (2011) uses past research to suggest that skin sensitivity, the influence of sunlight on one's body including endocrine function, outdoor activity, sociability, decreased clothing, and selective immigration (p. 9) are all potential variables brought on by geography that may foster differences in the perception and enactment of touch behavior. For instance, it is more likely that someone will feel a touch when wearing little or no clothing, and therefore it is more useful/ consequential to engage in touch with them. In addition, sunlight has been shown to have a positive influence on human affiliativeness and libidinousness (Andersen, 2011) and temperature has been shown to increase touch frequency and diversity (Sorokowska et al., 2021). Lastly, migratory patterns reflect a tendency for individuals to migrate to similar climate zones as those they moved from (Andersen, 2011). The considerably tactile Fore of Papua New Guinea provide an example of a culture shaped by a temperate climate with ample sunlight, sparse clothing, abundant outdoor activity, and sociability across their lifespan (Sorenson, 1979). Understanding the relationship between geographic environments and nonverbal behavior aids in understanding what we see in other regions and how we might approach communication on different soils.

\subsection{Cultural Indulgence and Touch}

Cultural indulgence, the degree to which societal norms restrain or enable individual's expressions and fulfillment of their immediate urges (Minkov \& Hofstede, 2011), is uniquely positioned to address public touch variations around the globe. For example, South Koreans' strong social norms against outward public displays of immediacy, emotion, and affection, have been contrasted with those in the United States, who show far less restricted public displays of emotional affection (Kim, 1977; Matsumoto, Takeuchi, Andayani, Kouznetsova, \& Krupp, 1998; Merkin, 2009). It is no surprise then that South Korea has an estimated indulgence score of 29, while the US doubles that, with an estimated score of 68 (out of 100 - maximum indulgence) (Hofstede, 2011). In the current study, the number of times individuals were observed touching each other, along with how many body locations were touched was higher in countries with higher indulgence scores. Because cultural indulgence did not correlate with latitude, our data suggests that it is a unique predictor of tactile behavior when comparing cultural norms. In general, values of indulgence appear related to more open and frequent communication using touch.

Our findings on indulgence run parallel to recent research illustrating the relationship between cultural conservatism and religiosity with less affective touch diversity across intimate and nonintimate relationships (Sorokowska et al., 2021). Sorokowska et al. (2021, p. 13) suggest that lower reports of touch communication in more conservative and religious cultures may represent a "constellation of certain psychological dispositions that increase some individuals' need for control and uncertainty reduction." They continue, indicating that conservatism and religiosity may engender more formal social norms with less freely and diversly expressed affective behavior.

In a related vein, Burleson, Roberts, Coon, and Soto (2018), using a cross-cultural sample of college women, illustrate how Mexican American ethnocultural norms encourage comfort with affectionate touch in public spaces to a greater degree than European American ethnocultural norms. Though it was not measured in Burleson et al. (2018), it is worth noting that cultural indulgence for Mexico is scored as a 97, while the United Kingdom and France are scored as 69 and 48 respectively (Hofstead, 2011). In the current sample, we found that in more indulgent cultures, $\mathrm{p}$-females were observed initiating touch significantly more often in both cross- and same- p-sex dyads. This effect was not observed for males. It is plausible that as a culture takes on more indulgent values related to nonverbal, affective behaviors, tactile restrictions leveled more heavily toward $\mathrm{p}$-females become more relaxed. This line of reasoning is consistent with prior research showing that women have more freedom of expression in more feminine and liberal cultures (Andersen, 2011; Hofstede, 2001; Sorokowska et al., 2021).

\subsection{Limitations and Future Directions}

This study has important limitations that bear careful consideration. First, the sample, though one of the largest of its kind, is restricted in its capacity to generalize beyond the current sample data. When conducting any research of a global nature it is imperative to select as many diverse locations as possible to eliminate 
confounding and mitigating influences. Despite a limited sample, we were able to capture a large and diverse number of countries that varied in latitude and cultural indulgence- our two key variables.

This study is also limited by its design, which trades the benefit of garnering personal and relational information afforded by proximally observing individuals, for a broader series of locations and potential to target geographically driven difference in tactile behavior. In other words, although some individual characteristics were not accounted for or had to be interpreted by coders, the method of aggregating data across multiple locations and multiple instances offered a means to explore the influences of latitude and indulgence directly. In addition, the selection of bars as a location to observe touch, due to their social nature and the presence of alcohol, limits the generalizability of the findings to other environments. By selecting bars with relatively equivalent characteristics, we were able to maintain a degree of experimental control over the environments that we observed. Finally, it is critical to understand that the data from this study are representative of tactile differences at a macro level and therefore have the strongest utility when comparing countries, not individuals.

It is important that future research related to touch and nonverbal communication continues to approach cultural variation using a combination of micro and macro methods to balance the influence of idiosyncratic, relational, and cultural forces. Longitudinal research would be useful in helping to understand the temporal flow between cultural values and behavior. For example, time series data could illuminate what values drive and flow from cultural indulgence to influence attitudes toward touch.

\subsection{Conclusion}

Culture is one of only several variables capable of addressing arguments related to basic notions of what nature and nurture contribute to variations in communication behaviors. For this study touch behavior was monitored via webcams in bars at differing latitudes around the world. Our findings replicate the relationship between latitudes closer to the equator and increased touch communication. In addition, we illustrate a relationship between the cultural variable of indulgence with increased touch. Higher cultural indulgence was also related to higher touch initiation by p-females in both same and cross p-sex interactions. Our findings connect with and add to a body of literature showing that cultural norms related to climate, conservatism, and religiosity share important relationships with restrictions and subsequent behavior with touch communication. Housed within these findings is the notion that geographical location may play a predictable role in motivating the development of cultural communication norms and behaviors. Research that approaches human communication from a global and cultural perspective has potential to help shed light upon the ongoing communication between humans, their environment, and one another.

\section{References}

Andersen, J., Andersen, P., \& Lustig, M. (1987). Opposite sex touch avoidance: A national replication and extension. Journal of Nonverbal Behavior, 11, 89-109. https://doi.org/10.1007/BF00990960

Andersen, P. A., \& Wang, H. (2006). Unraveling Cultural Cues: Dimensions of Nonverbal Communication across Cultures. In LA. Samovar \& R. Porter (Eds.), Intercultural Communication: A Reader (11th ed., pp. 250-266). Wadsworth.

Andersen, P. A. (2011). Tactile Traditions: Cultural differences and similarities in haptic communication. In M. Hertenstein (Ed.), Handbook of Touch (pp. 351-371). Springer Publishing.

Andersen, P. A., Lustig, M. W., \& Andersen, J. F. (1990). Changes in latitude, changes in attitude: The relationship between climate and interpersonal communication predispositions. Communication Quarterly, 38, 291-311. https://doi.org/10.1080/01463379009369768

Assaad, J. M., Pihl, R. O., Séguin, J. R., Nagin, D. S., Vitaro, F., \& Tremblay, R. E. (2006). Intoxicated behavioral disinhibition and the heart rate response to alcohol. Experimental and Clinical Psychopharmacology, 14(3), 377. https://doi.org/10.1037/1064-1297.14.3.377

Burleson, M. H., Roberts, N. A., Coon, D. W., \& Soto, J. A. (2019). Perceived cultural acceptability and comfort with affectionate touch: Differences between Mexican Americans and European Americans. Journal of Social and Personal Relationships, 36(3), 1000-1022. https://doi.org/10.1177/0265407517750005

Field, T. (1999). American adolescents touch each other less and are more aggressive toward their peers as compared with French adolescents. Adolescence, 34(136), 753-753.

GetLatLong. (n.d.). Retrieved from https://getlatlong.net/ 
Gokmen, Y., Baskici, C., \& Ercil, Y. (2021). The impact of national culture on the increase of COVID-19: A cross-country analysis of European countries. International Journal of Intercultural Relations, 81, 1-8. https://doi.org/10.1016/j.ijintrel.2020.12.006

Hall, E. T. (1966). The Hidden Dimension (2nd ed.). Garden City, NY: Anchor/Doubleday.

Hall, E. T. (1973). The Silent Language (Reissue ed.). New York: Anchor.

Hayes, A. F., \& Krippendorff, K. (2007). Answering the call for a standard reliability measure for coding data. Communication Methods and Measures, 1, 77-89. https://doi.org/10.1080/19312450709336664

Hofstede, G. (2001). Culture's Consequences: Comparing Values, Behaviors, Institutions and Organizations Across Nations. Thousand Oaks, CA: Sage.

Hofstede, G. (2011). Dimensionalizing cultures: The Hofstede model in context. Online readings in psychology and culture, 2(1), 8. https://doi.org/10.9707/2307-0919.1014

IJzerman, H., \& Semin, G. R. (2009). The thermometer of social relations: Mapping social proximity on temperature. Psychological science, 20(10), 1214-1220. https://doi.org/10.1111/j.1467-9280.2009.02434.x

Jones, S. E., \& Yarbrough, E. (1985). A naturalistic study of the meanings of touch. Communication Monographs, 52, 19-56. https://doi.org/10.1080/03637758509376094

Kim, K. H. (1977). Misunderstanding in nonverbal communication: America and Korea. Paper in Linguistics, 10(1-2), 1-22. https://doi.org/10.1080/08351819709370437

Lustig, M., \& Andersen, P. (1990). Generalizing about communication apprehension and avoidance: Multiple replications and meta-analyses. Journal of Social Behavior and Personality, 5, 309-340. Retrieved from https://www.proquest.com/openview/4f651d0b979eab85939a8f0bbb01f2be/1?pq-origsite=gscholar\&cbl=1 819046

Matsumoto, D., Takeuchi, S., Andayani, S., Kouznetsova, N., \& Krupp, D. (1998). The contribution of individualism-collectivism to cross-national differences in display rules. Asian Journal of Social Psychology, 1, 147-165. https://doi.org/10.1111/1467-839X.00010

McDaniel, E., \& Andersen, P. A. (1998). International patterns of interpersonal tactile communication: A field study. Journal of nonverbal behavior, 22(1), 59-75. https://doi.org/10.1023/A:1022952509743

Merkin, R. S. (2009). Cross-cultural communication patterns-Korean and American Communication. Journal of Intercultural Communication, (20). Retrieved from https://www.immi.se/intercultural/nr20/merkin.htm

Miller, M. J., Denes, A., Diaz, B., \& Buck, R. (2014). Attachment style predicts jealous reactions to viewing touch between a romantic partner and close friend: Implications for internet social communication. Journal of nonverbal behavior, 38(4), 451-476. https://doi.org/10.1007/s10919-014-0196-y

Miller, P. M., Commons, M. L., \& Gutheil, T. G. (2006). Clinicians' perception of boundaries in Brazil and the United States. Journal of the American Academy of Psychiatry Law, 34, 33-42. Retrieved from https://web.archive.org/web/20170813141536id_/http://jaapl.org/content/jaapl/34/1/33.full.pdf

Minkov, M., \& Hofstede, G. (2011). The evolution of Hofstede's doctrine. Cross Cultural Management: An International Journal, 18(1), 10-20. https://doi.org/10.1108/13527601111104269

Montagu, A. (1972). Touching, the human significance of the skin. Perennial Library.

O'Brien, R. M. (2007). A caution regarding rule of thumb for variance inflation factors. Quality and Quantity, 41, 673-690. https://doi.org/10.1007/s11135-006-9018-6

Remland, M., Jones, T., \& Brinkman, H. (1995). Interpersonal distance, body orientation, and touch: effects of culture, gender, and age. The Journal of Social Psychology, 3, 281-297. https://doi.org/10.1080/00224545.1995.9713958

Shutter, R. (1977). Proxemics and tactility in Latin America. Journal of Communication, 26(3), 46-52. https://doi.org/10.1111/j.1460-2466.1976.tb01902.x

Sorenson, E. R. (1979). Early tactile communication and the patterning of human organization: a New Guinea case study. In Margaret Bullowa (Ed.), Before speech (pp. 289-306). Cambridge University Press: New York. 
Sorokowska, A., Saluja, S., Sorokowski, P., Frąckowiak, T., Karwowski, M., Aavik, T., ... \& Croy, I. (2021). Affective Interpersonal Touch in Close Relationships: A Cross-Cultural Perspective. Personality and Social Psychology Bulletin. https://doi.org/10.1177/0146167220988373

Sorokowska, A., Sorokowski, P., Hilpert, P., Cantarero, K., Frackowiak, T., Ahmadi, K., ... \& Pierce Jr, J. D. (2017). Preferred interpersonal distances: a global comparison. Journal of Cross-Cultural Psychology, 48(4), 577-592. https://doi.org/10.1177/0022022117698039

Suvilehto, J. T., Glerean, E., Dunbar, R. I., Hari, R., \& Nummenmaa, L. (2015). Topography of social touching depends on emotional bonds between humans. Proceedings of the National Academy of Sciences, 112(45), 13811-13816. https://doi.org/10.1073/pnas.1519231112

Suvilehto, J. T., Nummenmaa, L., Harada, T., Dunbar, R. I., Hari, R., Turner, R., ... \& Kitada, R. (2019). Cross-cultural similarity in relationship-specific social touching. Proceedings of the Royal Society B, 286(1901), 20190467. https://doi.org/10.1098/rspb.2019.0467

Watkins, C. D., Leongómez, J. D., Bovet, J., Żelaźniewicz, A., Korbmacher, M., Varella, M. A. C., ... \& Bolgan, S. (2019). National income inequality predicts cultural variation in mouth to mouth kissing. Scientific reports, 9(1), 1-9. https://doi.org/10.1038/s41598-019-43267-7

\section{Copyrights}

Copyright for this article is retained by the author(s), with first publication rights granted to the journal.

This is an open-access article distributed under the terms and conditions of the Creative Commons Attribution license (http://creativecommons.org/licenses/by/4.0/). 